NOTICE: this is the author's version of a work that was accepted for publication in Scientometrics. Changes resulting from the publishing process, such as corrections, structural formatting, and other quality control mechanisms may not be reflected in this document. Changes may have been made to this work since it was submitted for publication. A definitive version was subsequently published in Scientometrics (2018) 117: 1793. https://doi.org/10.1007/s11192-018-2915-3

\title{
THE INFLUENCE OF ELFREDA CHATMAN'S THEORIES: A CITATION CONTEXT ANALYSIS
}

\author{
Aurora González-Teruel \\ History of Science and Documentation Department, University of Valencia, \\ Blasco Ibáñez, 17, 46010 Valencia, Spain \\ agonzal@uv.es \\ Orcid ID: 0000-0001-9304-2928 \\ Francisca Abad-García \\ History of Science and Documentation Department, University of Valencia, \\ Blasco Ibáñez, 17, 46010 Valencia, Spain \\ abad@uv.es \\ Orcid ID: 0000-0001-5611-4996
}

\begin{abstract}
The range of theoretical frameworks currently being used by researchers into information behaviour is abundant and diverse. We need to examine thoroughly the contribution of theories and models to further research, as this would help to improve future investigations in the field. This paper adopts this approach, by thoroughly examining the influence that Elfreda Chatman's three middle-range theories have had on subsequent research. A citation context analysis was carried out on the basis of those received by Information poverty theory, Life in the round theory and Normative behaviour theory. Analysis covered the year of publication, the type of work and the subject-matter of the citing documents. The cites in context or theoretical incidents were analysed for frequency of citation in citing documents, the content of Chatman's work being cited, the context co-citation analysis, the citation style and the citation location. The analysis of citation in context has allowed us to draw a distinction between the author and her work, while verifying that not all cites are the same. These differences reflect the unequal relevance of these theories to subsequent research.
\end{abstract}

\section{Keywords}

Information behaviour, theory, Elfreda Chatman, Citation context analysis

\section{INTRODUCTION}

Research on information behaviour (IB) came to be noted, by the end of the 20th century, as an area of study with a mostly theoretical basis, in the context of Library and Information Science (LIS) (McKechnie, Pettigrew and Joyce, 2001). This trend continued into the early years of the 21st century, with works of a theoretical character the most widely cited in literature on the subject (González-Teruel, González-Alcaide, Barrios, \& Abad-García, 2015). The source of this theory has mainly been other social sciences such as sociology, psychology, and education. It is however also very common for empirical research to generate models and theories based on the observation of users in specific contexts (Case \& Given, 2016).

The theories put forward by Elfreda Chatman are among those that have been cited most in the field of IB (González-Teruel et al., 2015). She researched the IB among various populations in the context of 
everyday life, paying particular attention to impoverished populations. She also added theories from other social sciences to her investigations, resulting in turn in three middle-range theories: Information Poverty (Chatman, 1996), Life in the Round (Chatman, 1999) and Normative Behaviour (Burnett, Besant \& Chatman, 2001). These theories represent the social perspective in the IB studies (Pettigrew, Fidel \& Bruce, 2001). The Information Poverty Theory (IPT) has its roots in a serie of ethnographic studies focused on the observation of the IB of three social groups: poor workers, female janitors and retired women (Chatman, 2000). The results of these studies, together with the adoption of "insider" and "outsider" as sociological concepts, were used by Chapman to propose the core concepts of this theory: secrecy, deception, risk-taking and situational relevance. Secrecy and deception are concepts that refer to self-protection mechanisms that are used to maintain privacy and hide reality. On the other hand, the "risk-taking" consists in the acceptance or rejection of an innovation depending on the perception of the cost versus the benefit it provides. Finally, "situational relevance" is the concept that explains the perception of the interest towards a certain information depending on its usefulness to solve a problem given a specific situation. All of them are factors upon which we can observe information flows in small communities, as well as providing the foundations of the information poverty (Chatman, 1996).

Moreover, "Life in the Round Theory" (LRT) was developed from the observation of a group of prisoners in a maximum-security prison (Chatman 1999). The life in the round is a "public form of life in which certain things are implicitly understood" (Chatman, 1999, p.212). Its members are considered insiders, people who use their understanding of social norms to improve their own role. Plus, they are the reference to observe the information flows in a social world. The theory was based on four concepts: small world, social norms, worldview and social types. The small world is a world in which its members share a common vision of reality. The social norms are acceptable behaviours in a certain context. The "worldview" refers to the collective perception of the members of a social group in regards to what is important or what is trivial. Last, the social types are the classification of a social world members, given the way they behave and share information. The third of the proposed theories was the "Normative Behavior Theory" (Burnett, Besant \& Chatman, 2001). The "normative behavior" refers to that behavior that is considered by the members of a social world as the most appropriate for that particular context, which conditions it and helps explain it. This is an extension of the LRT that, in addition to developing a series of theoretical assumptions, proposes an empirical approach to examining virtual communities and the world of feminist booksellers in order to test the theory ((Burnett, Besant \& Chatman, 2001).

Eldreda Chatman is, despite her premature death in 2002, one of the most widely-recognised researchers in the field. It has been said of her that she is "one of the most prominent figures in ELIS [everyday life information seeking] studies" (Savolainen, 2008, p. 158), "a pioneer in LIS theory development” (Fulton, 2010 , p. 238), whose "life and work exemplified the scholar in practice" (Fulton, 2010, p. 238), and someone whose "legacy continues to frame the research agenda and set the standards of information behavior scholars" (Burnett, Fisher, Fulton \& Hersberger, 2007, p. 1). However, Burnett, Jaeger and Thompson (2008) stated that the concepts proposed by Chatman were used but not discussed, and that most of the references to her research simply recognised her ideas without proposing anything else based on them (Burnett et al., 2008). These statements reflect in part the current status of research on IB; characterised by an abundance of theories and theoretical models, with varying ontological and epistemological budgets and a certain superficiality in the way in which they are used and discussed (Case \& Given, 2016).

Indeed the range of theoretical frameworks currently being used by researchers into information behaviour is diverse to the point of being unmanageable. Fidel (2012) affirms that the theoretical landscape is like a bazaar containing a wide range of theoretical constructs and conceptual and methodological frameworks. Likewise, Case and Given (2016) asserts that theories form communities of discourse, which allow results to be discussed and compared. It is however extremely difficult to make such comparisons, given that the theories concerned are so abundant in number and based on such diverse philosophical assumptions. This in turn increases the difficulty of obtaining cumulative results that favour advancement in the understanding of the research object.

With this in mind, we need to examine thoroughly the contribution of theories and models to further research on IB, as this would help to improve future investigations in the field. It will also permit the development of approaches that test and validate previous theories and models, rather than designing continuous new theoretical approaches with no connection to each other or their predecessors. This paper adopts the former approach, by thoroughly examining the influence that Chatman's three theories have had on subsequent research. As Spink and Cole (2005) stated, for a field to move forward scientifically, it is important to examine the strengths and weaknesses of its theoretical bases in order to move towards an integrated perspective (p. 26). 
Several studies have attempted to describe theoretical and conceptual growth in research into information behaviour. Vakkari (1998) studied the theoretical growth of a research programme that focused on the effects of task complexity on information source use, based in this respect on Wagner's and Berger's model of theory growth from sociology. Savolainen has more recently (2016a) carried out research, using conceptual analysis, into how the model of information seeking formulated by Ellis (1989) has been used and reworked in the course of subsequent investigation. This researcher also analysed the integration of several models of IB as an example of theoretical growth in information research (Savolainen, 2016b).

Chang (2013) investigated, from a bibliometric perspective, the influence that the main concepts set out in Taylor's 1968 article entitled "Question-negotiation and information seeking in libraries" have had on LIS. Chang (2016) has more recently focused on the same objective by considering Zipf's book "Human Behaviour and the Principle of Least Effort", published in 1949. Both studies employed context citation analysis (CCA) which can be used, according to Zhang, Ding and Milojevic (2013), “...to operationalise and measure concepts and intangible connotations, as well as the intellectual process of transfer and exchange of knowledge" (p. 1495).

If we were to track the content of the citations generated by Elfreda Chatman's three theories, it would allow us to go more deeply into the use that subsequent research has made of her work, while assessing its contribution, determining its degree of assimilation and establishing future lines of research designed to increase our knowledge of its existing theoretical foundations. As McCain (2011) states, "when a publication's citation history is analysed in terms of the sources of the citing works, it is possible to trace the spread of the ideas contained across disciplinary boundaries as well as over time" (p. 1413), CCA is also a complement to traditional citation analysis which allows for syntactic and semantic analysis, as well as a quantitative and qualitative examination of the content of citations (Zhang et al., 2013).

CCA has been used to observe the influence of particular authors or studies on subsequent research. McCain and Salvucci (2006) focused on "The Mythical Man-Month" of Brooks (1975) to show the diversity of concept symbols that this text has represented over the years and across disciplines. Anderson (2006) deals with the works of Karl Weik and citations in the context of studies published in organization studies journals. Tsay (2009) analysed the works of Ted Nelson and the influence of the concept of hypertext. Rosenbaum (2010) studied Anthony Giddens' influence on LIS. Anderson and Sun (2010) analysed citations in the context of Walsh and Ungson's work (1991) on organisational memory. Sieweke (2014) carried out research into Pierre Bourdieu's influence on management and organisation studies. Finally, Lu, Ding and Zhang (2017) focused on the citation dynamics of Hirsh (2005) over a period of nine years.

The research question posed by this paper, in this context, is as follows: What influence have information poverty theory, life in the round theory and normative theory had, and to what extent have they been assimilated? Quite apart from Chatman's relevance as a researcher, the untimely interruption of her career, and therefore of her scientific production, will allow us to study her work in a "controlled environment", uncontaminated by the possible influence of subsequent research.

\section{METHODS}

A citation context analysis was carried out on the basis of those received by Chatman (1996), Chatman (1995) and Burnett et al., (2001). Other earlier or later work could have been taken as a reference, including for example Chatman (2000), in which she reviews her research program. However, in order to ensure the accuracy of the sample and the clear relationship between citing document and theory, the decision was made to include only, as work cited, the three articles that marked the initial formal appearance of concepts and propositional statements relating to such theories. This decision allows us to carry out a differentiated analysis for each theory and the comparison between them.

\section{Selection of citing works}

Citing works were retrieved from the Core Collection of WoS and Scopus on 16 November 2017. A total of 373 unique documents was obtained after eliminating any overlap. Four of these documents were eliminated on account of being published in languages unknown to the authors (German, Farsi, Japanese and Hungarian), as were 20 books and 12 book chapters, due to difficulties relating to their retrieval and the analysis of citations in context. The authors subsequently obtained and examined the full text of 337 articles, conference proceedings and chapters of serials. Five of these were eliminated for not citing any of the three works by Chatman. The authors finally analysed 332 documents, of which 236 cited Chatman (1996), with 161 citing Chatman (1999) and 49 mentioning Burnett et al. (2001). In order to facilitate the 
reading of results, Chatman (1996) was given generic treatment, as were information poverty theory (IPT), Chatman (1999), life in the round theory (LRT), Burnett et al. (2001) and normative behaviour theory (NBT).

\section{Analysis of citing documents and citations}

The citing documents and citations were analysed in context, as shown in table 1.

\section{CITING DOCUMENT \\ Publication year \\ Type of work ${ }^{4}$ reports. way). theory or model. the approach concerned). \\ Other: Case studies, panels, editorials, etc.

\begin{tabular}{|l|l|} 
Subject $^{6}$ & 1. LIS / Not LIS \\
& 2. Not LIS: major thematic areas of SJCR
\end{tabular}

Empirical: Reports of original research that describe the systematic gathering and analysis of data for a particular purpose not considered or addressed in previous

Bibliographical: Bibliometric studies, content analysis, literature reviews, studies which analyse data obtained by others (secondary studies) or a bibliographical selection and comment of a specific aspect, in a systematic or narrative manner (or

Theoretical: Literature-based studies that analyse the development of theories or concepts which delimit or expand theoretical constructs, or which present a new

Methodological: Studies that present new methodological approaches to the study of a problem (while introducing empirical data only for the purpose of illustrating

THEORETICAL INCIDENT (CITED IN CITING DOCUMENT)

Frequency of

citation

Content cited and

context co-citation

analysis

Citation style

a) Direct quotation:

According to Chatman, life in the round is "a life with an enormous degree of imprecision and, surprisingly, accepted levels of uncertainty" (1999, p. 211).

b) Specific, but interpreted, mention of a single work by Chatman Prisons as institutions represent a "small world" or microsociety, in which activities are routine and predictable and where cohesion is maintained through social control (Chatman, 1999)

c) Specific, but interpreted, mention of various works by Chatman Chatman's (1986, 1991, 1992, 1996, 1999) extensive empirical studies, for example, provide a firm basis for her theories.

d) Non-specific mention Among these terms are "setting" (e.g. Bystrom, 1997; Davies \& McKenzie, 2004; McKenzie, 2004; Pettigrew, 2000), "environment" (e.g. Janes \& Silverstein, 2003; Lamb, King, \& Kling, 2003; Rieh, 2004; Taylor, 1991), "information world" or "life-world" (e.g. Chatman, 1996; Kari \& Savolainen, 2003; Lievrouw, 2001; Talja, 1997), and "information ground" (e.g. Fisher, Naumer, Durrance, Stromski \& Christiansen, 2005; Fisher, Durrance \& Hinton, 2004 and Pettigrew 1999).

Citation location

1. Abstract, introduction, literature review, theoretical framework, methods, results, discussion or conclusion

2. a) Introduction and literature review $(\mathrm{I}+\mathrm{L})$ : b) Theoretical framework and methods $(\mathrm{T}+\mathrm{M})$ and $\mathrm{c})$ Results, discussion and conclusion $(\mathrm{R}+\mathrm{D}+\mathrm{C})$

Table 1 Analysis of citing documents and theoretical incidents 
Analysis covered the year of publication, the type of work and the subject-matter of the citing documents. The type of work that the citing documents referred to was classified in accordance with the categories of the APA style manual (APA, 2010). When it came to allocating thematic categories, citing documents were first classified as: a) LIS if published in bibliographical items classified as "Information Science \& Library Science" by the Journal Citation Report (JCR) or as "Library and Information Sciences" by the Scimago Journal \& Country Rank (SJCR) or as (b) Not LIS if the above failed to apply, in which case they were assigned to one of the 27 major thematic areas of the SJCR.

Once the citing documents have been analysed, the sentence in each one that includes a cite from any of Chatman's three works was identified. Each sentence was regarded as a theoretical incident or unit of register, understood to be the unit of significance being analysed or the segment of minimum content (Bardin, 1986). However, whenever a sentence preceding or subsequent to the same cited Chatman, it was included in each incident as a unit of context. The unit of context is the unit of understanding used for analysis of the unit of register, or the segment of the message whose size (greater than that of the unit of register) is ideal for grasping its precise significance (Bardin, 1986).

The citations in context or theoretical incidents were analysed for frequency of citation in citing documents, the context co-citation analysis, the content of Chatman's work being cited, the citation style and citation location of the citing documents with an IMRD structure.

Analysis of the cited content first involved extracting the most significant terms and expressions used by Chatman (1996), Chatman (1999) and Burnett et al. (2001). Three master lists were then generated; one for each theory, designed to standardise the terms and expressions used in the three cited works. This involved the merging of single-word synonyms and equivalent expressions, the combining of single and plural terms and the grouping together of generic and specific terms and expressions. The content cited in the theoretical incidents was then identified on the basis of each master list. This process of identification allowed us to establish: a) the absolute frequency with which the terms and expressions identified in the three works cited appeared in the theoretical incidents, and b) their relative frequency, that is to say, the frequency and percentage of incidents in which they appeared. Given that each theory is based on four concepts, which are in turn used to develop a series of propositional statements, we analysed the number and percentage of citing works and theoretical incidents in which these concepts appeared. The four core concepts for IPT are: secrecy, deception, situational relevance and risk-taking. These are small world, worldview, social norms and social types, in the case of LRT, and information behavior, social norms, worldview and social types in the case of NBT.

In order to reveal the relationships between the concepts that appear in the citing documents, a context co-citation analysis was performed, assuming that "The frequency with which a given combination [of concepts ] occurs in the sample of papers on the topic is a measure of the degree of consensus regarding the particular concept combination within the corpus" (Small, 1980, p. 183 ). Accordingly, the cooccurrences of the terms were extracted from the context of the documents. Subsequently, the co-citation network was generated. The nodes were the most significant terms that had been extracted previously and then links represent these co-occurrences. The Bibexcel software was used to obtain the co-occurrences between terms and the co-citation networks, and the Gephi software was used to graphically represent them.

Four categories based on Bonzi (1982) and Zhang et al. (2013) were established in order to determine the citation style. In the view of these authors, "...a reference that is cited by an article, but is not obviously mentioned in the text, can be considered less relevant than one that is discussed in depth within the text of the citing article" (Zhang et al., 2013, p. 1498). The final step was to identify the citation location in the structured documents. This was done by first establishing whether the theoretical incident appeared in the abstract, introduction, literature review, theoretical framework, methods, results, discussion or conclusion. After excluding the incidents that appeared in the abstract and in order to prevent the dispersion of results, the next step was to group them according to whether they appeared in : a) the introduction or literature review, given that both sections describe the general context of the research concerned; b) the theoretical or conceptual framework and methodology detailing the designrelated aspects of the research and/or c) the results, discussion and conclusion that contextualised the results obtained from the research.

\section{RESULTS}

\subsection{Citing documents}

\subsubsection{Year of publication}

Fig. 1 shows annual evolution of the documents that cited each of the three reference works. Information 
Poverty Theory (IPT) received the first citation in the year that saw the publication of the work of Chatman (1996), which was cited throughout the period being studied at an average rate of 10.7 citations per year. The annual frequency of these citations has been increasing to date, albeit with fluctuations. The picture for citations in the case of Life in the Round Theory (LRT) is similar, although the average annual citation rate has been 8.5 .

The corresponding annual figure for Normative Behaviour Theory (NBT) was 2.9. This obtained fewer citations than the first two theories (never exceeding five per year), with similar values up to 2017.

While IPT displays an annual average growth rate of $11.0 \%$ therefore, the figure for LRT is $6.6 \%$, with $2.6 \%$ for NBT.

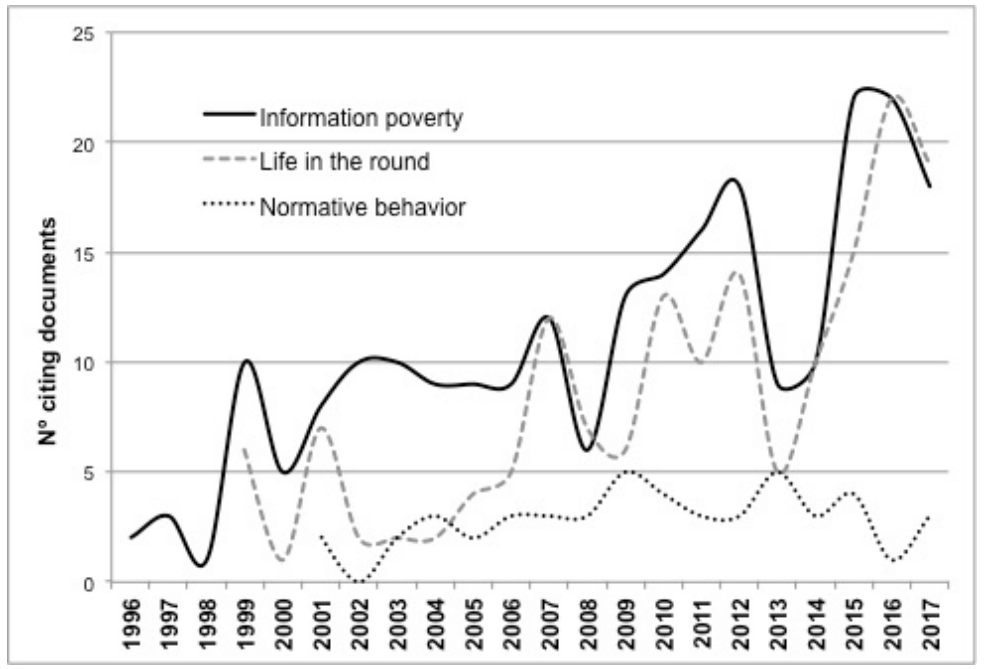

Fig. 1 Evolution of citing documents

\subsubsection{Type of work}

Most of the citing documents relating to the three theories are empirical, followed by bibliographical and theoretical works. A smaller number of citing documents are works of methodology or other types of item (table 2).

\begin{tabular}{lrrrrrr}
\hline & \multicolumn{2}{c}{ IPT } & \multicolumn{2}{c}{ LRT } & \multicolumn{2}{c}{ NBT } \\
\hline & $\mathbf{N}$ & $\mathbf{\%}$ & $\mathbf{N}$ & $\mathbf{\%}$ & $\mathbf{N}$ & $\mathbf{\%}$ \\
Empirical & 144 & 61 & 99 & 61.1 & 23 & 46.9 \\
Bibliographical & 44 & 18.6 & 28 & 17.3 & 15 & 30.6 \\
Theoretical & 33 & 14 & 26 & 16.0 & 7 & 14.3 \\
Methodological & 7 & 3 & 5 & 3.1 & 1 & 2 \\
Other & 8 & 3.4 & 4 & 2.5 & 3 & 6.1 \\
\hline Total & $\mathbf{2 3 6}$ & $\mathbf{1 0 0}$ & $\mathbf{1 6 2}$ & $\mathbf{1 0 0 . 0}$ & $\mathbf{4 9}$ & $\mathbf{1 0 0}$ \\
\hline
\end{tabular}

Table 2 Type of citing document

Figs. 2, 3 and 4 show the evolution of these items according to the type of citing document for each theory.

It is noticeable, with respect to IPT, that most of the citing documents from the period concerned are empirical, and that their number increases over the period from 2006 to 2008. The second-most frequent type of work from the beginning of the time concerned is bibliographical, giving way to theoretical works after the same period. They have been the second-most important type of work since the period from 2012 to 2014. The presence of methodological and other types of work is merely anecdotal throughout this period.

Most LRT-related citing documents up to 2005 are bibliographical and empirical. The number of empirical works began to grow after the period from 2006 to 2008, and accounted for $71.4 \%$ of total works by the period from 2015 to 2017. Bibliographical and theoretical works alternate in terms of importance throughout this period, but without attaining the figures corresponding to empirical works. 
Finally, and with respect to NBT, most citing documents up to the period from 2009 to 2011 are bibliographical. The number of empirical works increased thereafter, but without attaining the figures of the previous theoretical works.

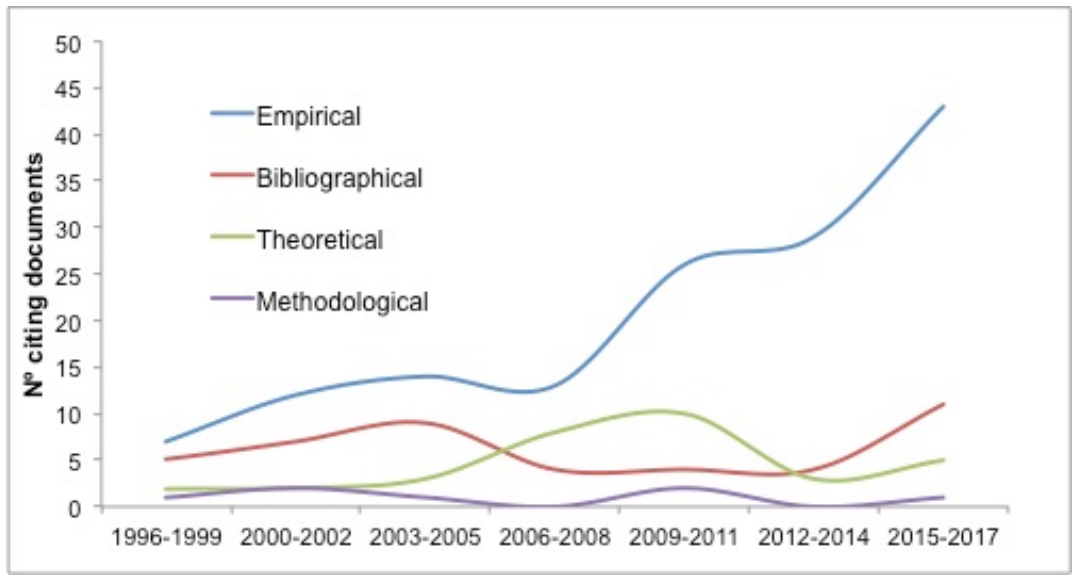

Fig 2 Type of document citing Information Poverty Theory

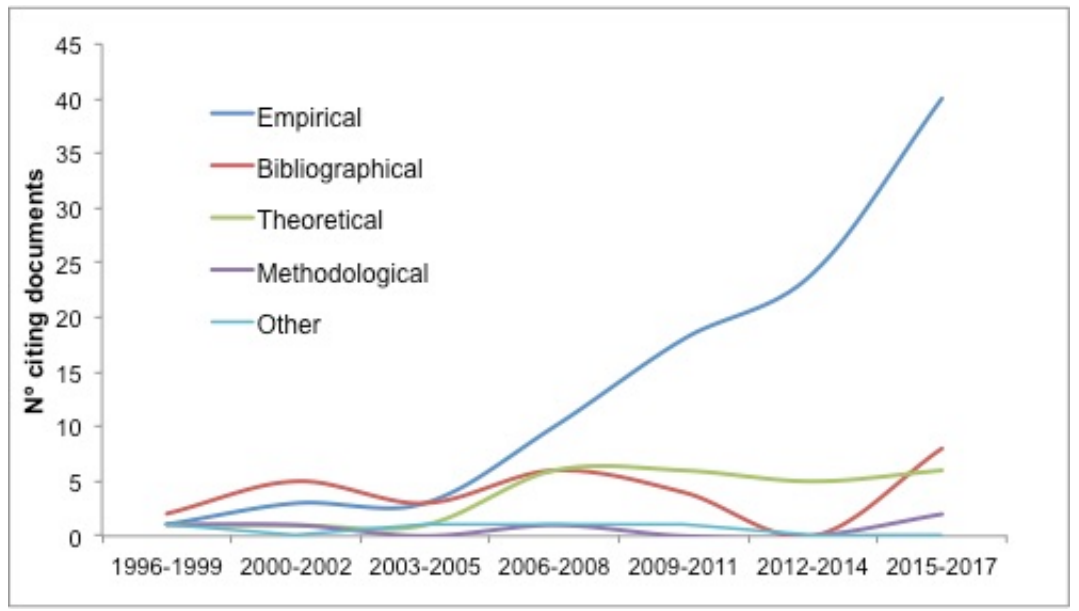

Fig 3 Type of document citing Life in the Round Theory

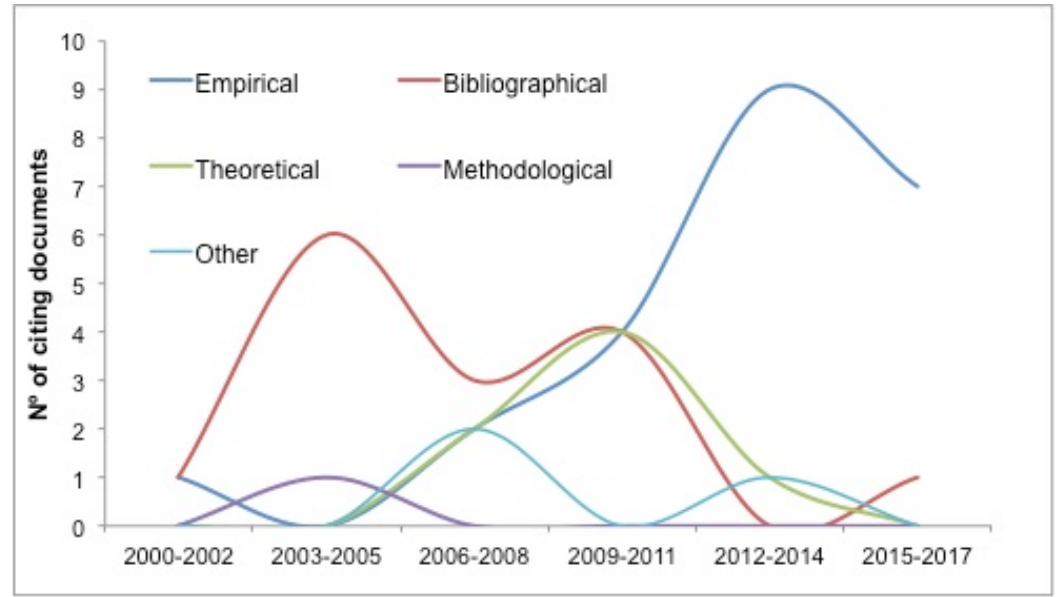

Fig 4 Type of document citing Normative Behaviour Theory

\subsubsection{Subjects}


$17.4 \%$ of the document citing IPT belong to an area other than LIS (41 documents, of which 31 are empirical, $75.6 \%$ ). In the case of LRT, the percentage is $10.5 \%$ (17 documents, 13 of them empirical, $76.5 \%$ ). Just three of the 49 documents cited NBT.

Fig. 5 shows the evolution of citing documents corresponding to different areas of LIS. Their impact has increased throughout the period, in the case of IPT and LRT, despite their very low figures. Table 3 shows the areas to which citing documents considered to be non-LIS belong.

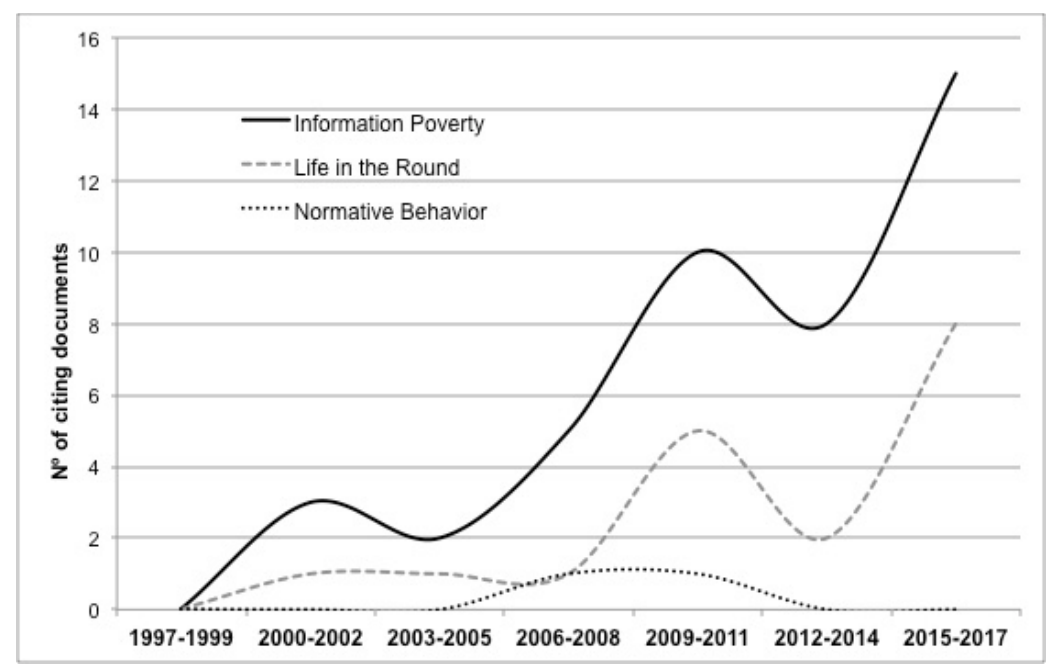

Fig 5 Citing works in publications other than LIS

Most of the citing works belong to the fields of social science and computer science, while medicine and arts and humanities, stand out in the case of IPT and LRT.

\begin{tabular}{lrrr}
\hline Subject area & IPT & LRT & NBT \\
\hline Agricultural and Biological Sciences & 2.4 & & \\
Arts and Humanities & 12.2 & 11.8 & \\
Business, Management and Accounting & 11.2 & 5.9 & \\
Computer Science & 31.7 & 47.1 & 33.3 \\
Decision Sciences & 9.8 & 5.9 & \\
Economics, Econometrics and Finance & 2.4 & 5.9 & \\
Engineering & 9.8 & & \\
Environmental Science & & 5.9 & \\
Health Professions & 2.4 & & \\
Mathematics & 2,4 & 5.9 & \\
Medicine & 19.5 & 11.8 & 33.3 \\
Psychology & 7.3 & 5.9 & \\
Social Sciences & 39.0 & 29.4 & 66.7 \\
\hline 3. Thematic areas, other than LIS, in which the citing works appeared
\end{tabular}

\subsection{Theoretical incidents}

Analysis of the citing documents revealed that some of them contained no citation in text, but rather the bibliographical reference in the final list only. The analysis of the frequency of citations, the content cited and the style of citation therefore refers to documents with citations in the text (table 4). Furthermore, not all the citing documents had an IMRD structure, so the analysis of the location of theoretical incidents refers to documents with citations in the text which also have an IMRD structure.

\begin{tabular}{cccccc}
\hline \multicolumn{2}{c}{ IPT } & LRT & \multicolumn{2}{c}{ NBT } \\
\hline $\begin{array}{c}\text { Analysed } \\
\text { documents }\end{array}$ & $\begin{array}{c}\text { Theoretical } \\
\text { incidents }\end{array}$ & $\begin{array}{c}\text { Analysed } \\
\text { documents }\end{array}$ & $\begin{array}{c}\text { Theoretical } \\
\text { incidents }\end{array}$ & $\begin{array}{c}\text { Analysed } \\
\text { documents }\end{array}$ & $\begin{array}{c}\text { Theoretical } \\
\text { incidents }\end{array}$ \\
\hline
\end{tabular}




\begin{tabular}{|c|c|c|c|c|c|c|}
\hline $\begin{array}{l}\text { Citing } \\
\text { documents } \\
\text { (CD) }\end{array}$ & 236 & & 162 & & 49 & \\
\hline $\begin{array}{l}\text { CD whith } \\
\text { cite in text }\end{array}$ & 225 & 452 & 158 & 323 & 49 & 95 \\
\hline $\begin{array}{l}\text { CD whith } \\
\text { cite in text } \\
\text { and IMRD } \\
\text { structure }\end{array}$ & 146 & 306 & 103 & 222 & 27 & 43 \\
\hline
\end{tabular}

\subsubsection{Frequency of citation}

There were 452 incidents in the 225 documents that cited IPT in the text (an average of two incidents per document). A total of 145 documents (64.4\%) contained just one theoretical incident, while $68(30.2 \%)$ contained between two and five incidents; with 12 documents $(5.3 \%)$ identified as containing six or more incidents. Veinot (2009) was, with 18 incidents, the document with the greatest number of theoretical incidents. This study used IPT as the theoretical basis for the research design.

There were 323 incidents in the 158 documents that cited LRT in the text (an average of two incidents per document). A total of 85 documents (53.8\%) contained one theoretical incident, while $63(39.9 \%)$ contained between two and five incidents; with ten documents $(6.3 \%)$ identified as containing six or more incidents. The document identified as containing the greatest number of theoretical incidents was Dankasa (2017), which used LRT as the theoretical basis for the research design in the same way that Veinot (2009) used IPT.

There were, finally, 95 incidents in the 49 documents that cited NBT in the text (an average of 1.9 incidents per document). A total of 32 documents $(65.3 \%)$ contained one incident, while $14(28.5 \%)$ contained between two and five incidents; with three documents $(6 \%)$ identified as containing six or more incidents. The document identified as containing the greatest number of theoretical incidents was Burnett, Jaeger, \& Thompson (2008), with 12 such items.

Fig. 6 shows how the figure for average incidents per document evolved throughout the period concerned. In the case of IPT and LRT, we can observe a slight progressive increase, albeit with fluctuations, with an average of one incident per citing document at the beginning of the period and respective averages of 2.7 (IPT) and 2.5 (LRT) at the end. The figure for NBT remained fairly constant throughout the period, with two peaks. The first of these, which occurred in 2008, corresponded to an average of 8.3 incidents per citing document. This increase in the average was caused by the 12 theoretical incidents of Burnett, et al. (2008), the seven of Burnett and Jaeger (2008) and the six of Burnett and Nocasian (2008). These are works in which the research being cited is essential. Some of these authors were also collaborators of Chatman. 


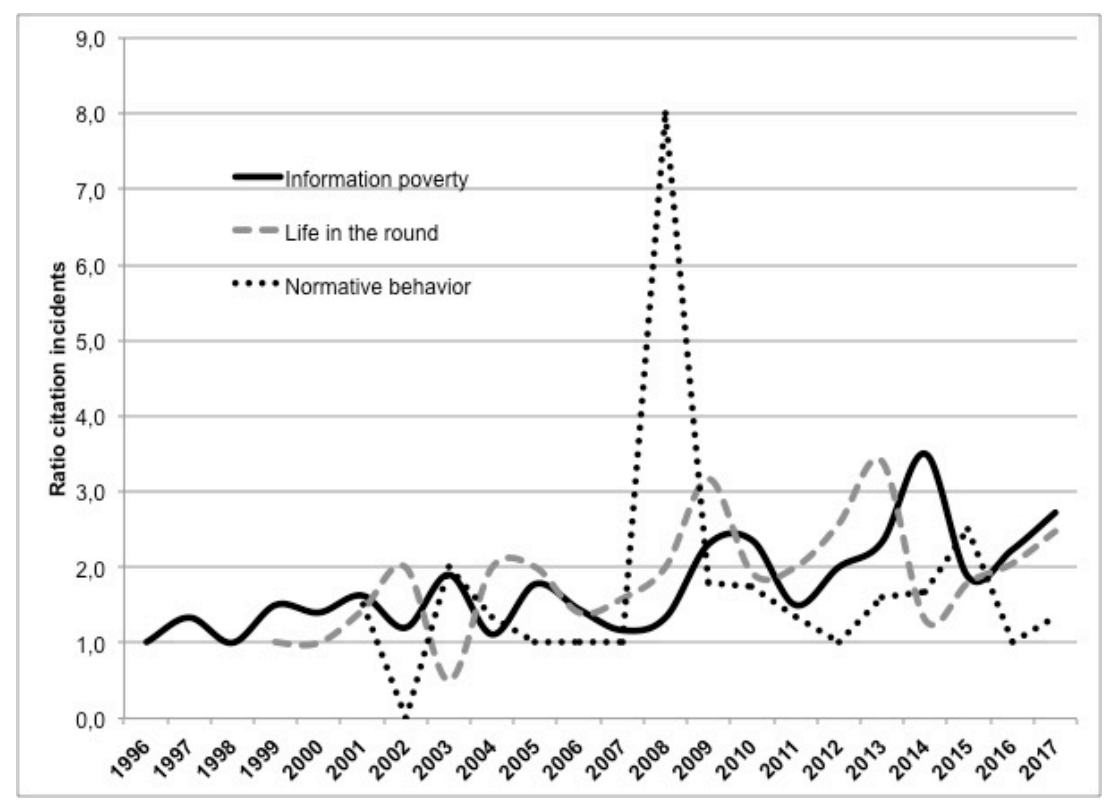

Fig 6 Evolution of average incidents per document

\subsubsection{Chatman's content cited}

Table 5 shows terms and expressions relating to Chatman's three theories that appear in at least $4 \%$ of the theoretical incidents extracted from the citing documents. These terms and expressions are three types.

The first type corresponds to terms and expressions that might be found in any specific LIS text, such as "information", "information-seeking behaviour", or "information sources". The second corresponds to those that belong to the discourse used to express the three theories. It can refer both to generic expressions ("information-poor", "information worlds" or "worlds"), previous studies whose results Chatman used as a basis for her theories ("women", "prison", "virtual communities" or "feminist booksellers"), or to the name of the theory concerned. Finally, the core concepts used as a basis for the propositional statements of the theories, along with others which, despite not actually being core concepts, support the theories concerned. These appear with a shaded background in table 5 .

In the case of IPT, the most-frequently occurring concepts are "outsider" and "insider", which appear in $18.4 \%$ and $13.5 \%$ of incidents respectively. These are followed by the concepts of secrecy $(9.5 \%)$ and deception $(7.3 \%)$, both of which are core concepts of the theory, along with situational relevance $(5.1 \%)$ and risk-taking $(4.9 \%)$. Other concepts that frequently underpin IPT are self-protection and social norms, which appear in $6.9 \%$ and $6.2 \%$ of the incidents respectively. The figures for theoretical incidents containing at least one of the four core concepts of IPT are 56 incidents $(12.4 \%)$ appearing in 36 documents $(16 \%)$.

The core concept of LRT that appears most frequently is "small world" (35.6\% of incidents), followed to a lesser extent by the concepts of "worldview" (13\% of incidents), "social norms" (12.7\% of incidents) and "social types" (4.3\%). Another frequently appearing concept is the one that gives the theory its name: "life in the round" (24.5\%), followed to a lesser extent by "insiders" $(8 \%)$ and "outsiders" $(6.5 \%)$. The figures for theoretical incidents containing at least one of the four core concepts of LRT are 148 incidents (45.8\%) appearing in 86 documents (38.7\%).

As a final point, the core concepts of NBT appear in at least $8 \%$ of incidents. These are, ordered from highest to lowest frequency of occurrence: "information behaviour" (28.4\%), "social norms" (16.8\%), "worldwide" (13.7\%) and "social types" (8.4\%). Other concepts that underpin NBT are: "small world", which is the one most frequently cited (47.4\%), "normative behaviour" (13.7\%) and "outsiders" (4.2\%). On the other hand, the concept of "insider" appears in only two cases. The figures for theoretical incidents containing at least one of the four core concepts of NBT are 46 incidents (48.4\%) appearing in 21 documents (42.8\%). 


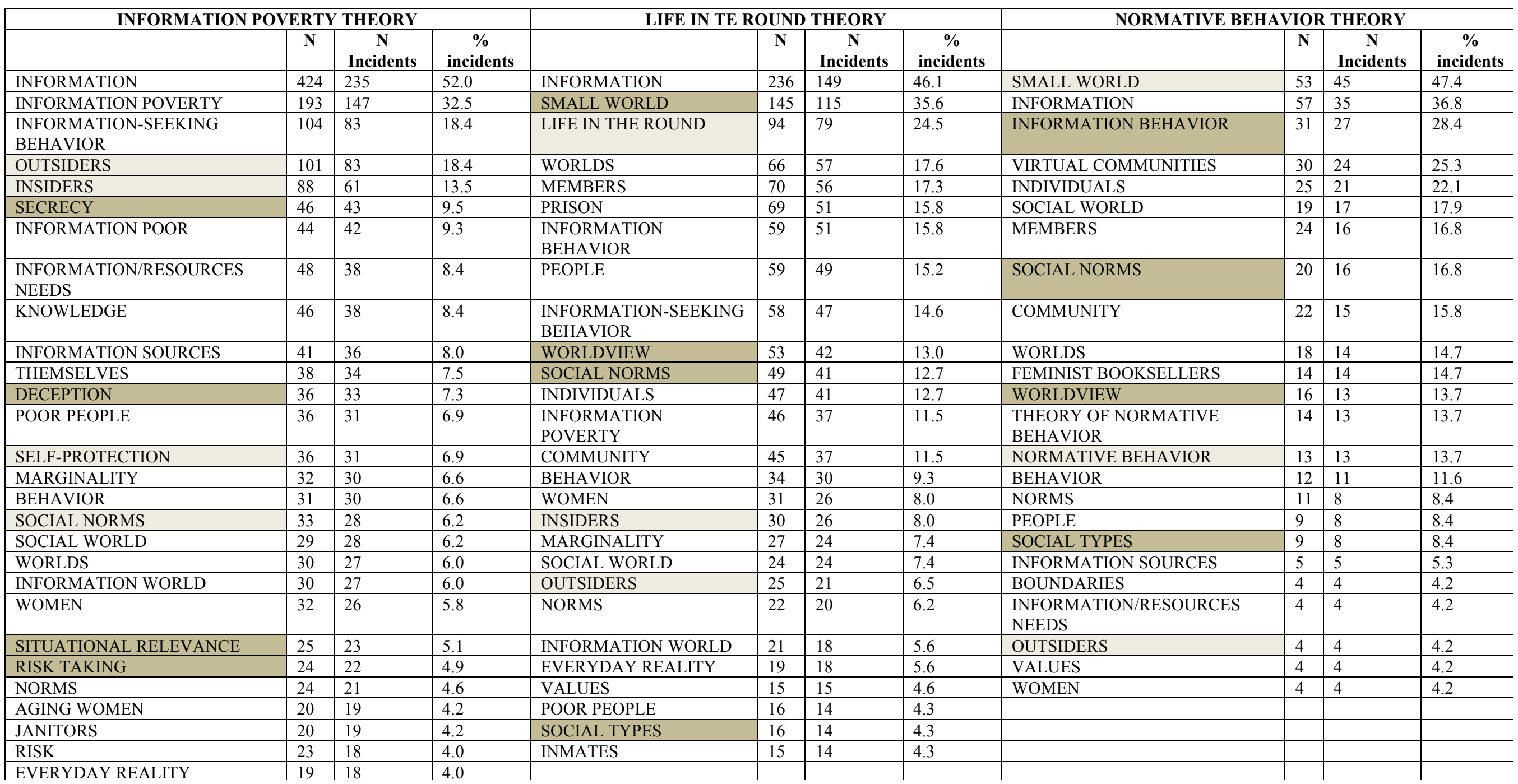


The analysis of the co-occurrences between the most frequent terms are shown in Figure X-Y-Z. For the three theories, only co-occurrences with a frequency greater than 2 have been included.

For the IPT, the greatest number of co-occurrences occurs between the term "Information" and the rest of the terms. Of these, the most frequent are: "Information seeking behavior" (56 co-occurrences), "Information poverty" (52) and "outsiders" (48). These relationships are followed by the co-occurrence between the terms "outsider"-"insider" (40). This is the most frequent relationship if we focus the analysis on the concepts of this theory. Moreover, we find less frequently the following relationships: "deception" and "secrecy" (23), "risk-taking" and "secrecy" (18), "deception" and "risk-taking "(16), "outsiders" and "secrecy" (16), and finally, "risk-taking" and "situational relevance" (16).

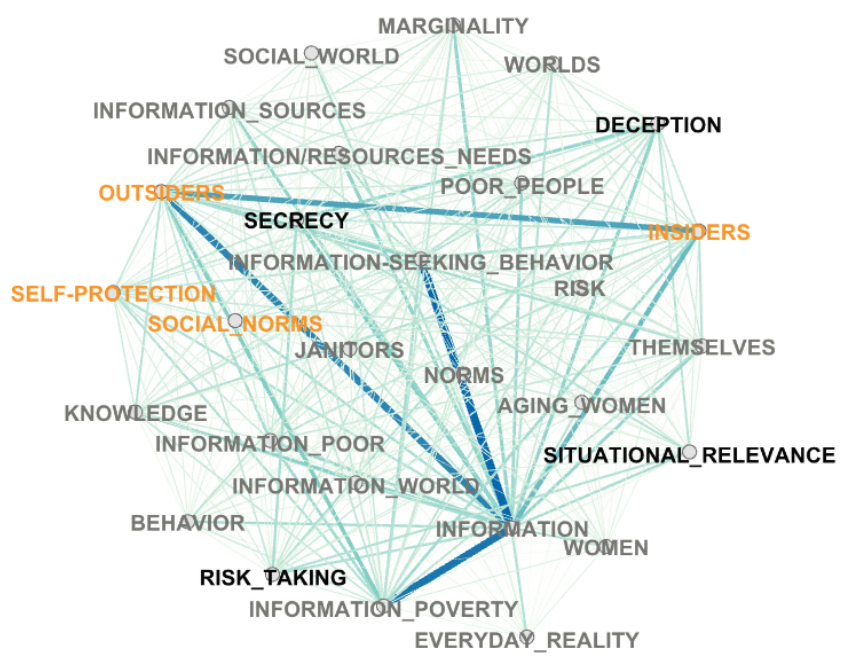

Fig 7 Information Poverty Theory co-citation network

In regards to the LRT, the most frequent co-occurrences occur between the term "information" and the following: "small world" (46 co-occurrences), "information behavior" (33), "life in the round" (29) and "worlds" (27). On the other hand, the most frequent co-occurrences between concepts occur between "small-world" and "worldview" (25 co-occurrences), "small-world" and "social norms" (24) and "smallworld" and "life in the round" (24).

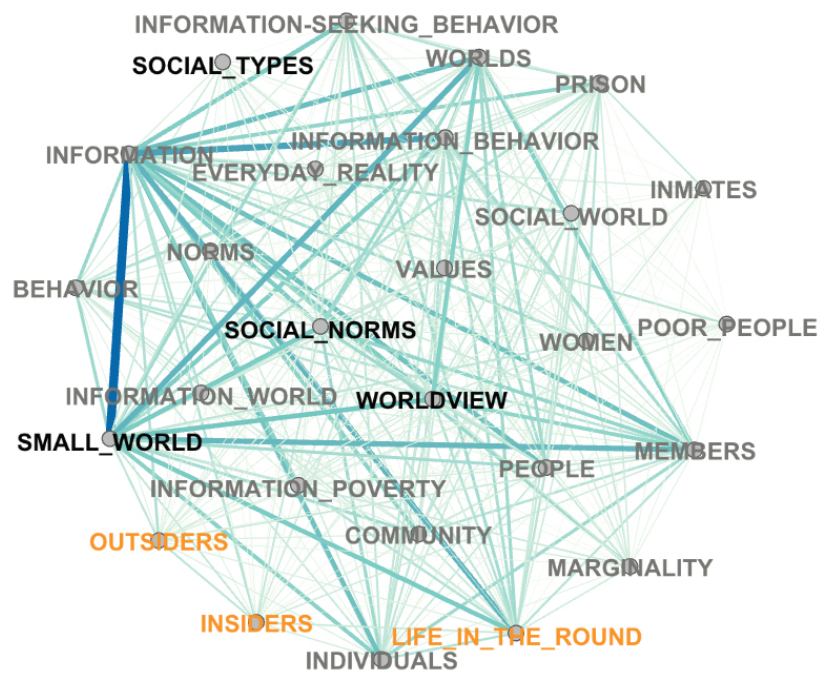

Fig 8 Life in the Round Theory co-citation network

Finally, the most frequent co-occurrences in the NBT occur between the concept "small world" and the following: "information" (15 co-occurrences), "information behavior" (12) and "members" (11). The 
most frequent co-occurrences among concepts, in addition to the aforementioned between "small world" and "information behavior", occur between "social norms" and "information behavior" (10) and between "small world" and "normative behavior" (9).

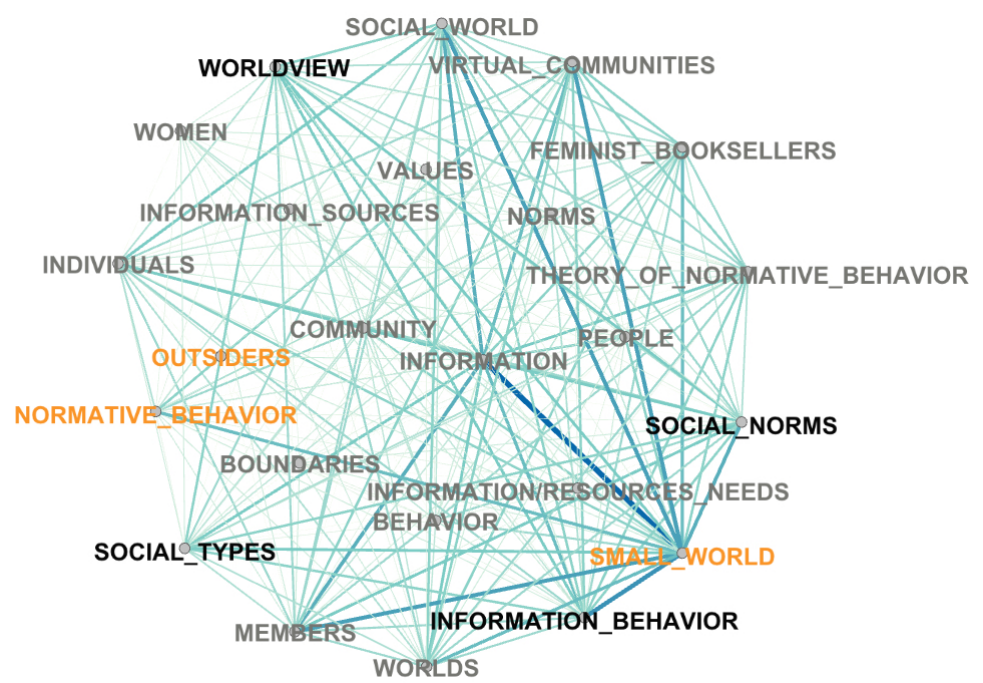

Fig 9 Normative Behavior Theory co-citation network

\subsubsection{Citation style}

The citation style that appears most frequently in the three theories is a specific, interpreted mention of a single work of Chatman (category B) (41.8\% IPT; 37.5\% LRT; 54.7\% NBT), followed by a non-specific mention in the case of IPT (category D) $(28.8 \%)$ and LRT $(25.7 \%)$ and direct quotation (category A) in the case of NBT (17.9\%) (table 6). The direct quotation is the least-frequently occurring citation style in theoretical incidents relating to IPT (12.8\%) and LRT (12.1\%).

\begin{tabular}{lcccccc}
\hline & & IPT & LRT & \multicolumn{2}{c}{ NBT } \\
\hline & $\mathbf{N}$ & $\mathbf{\%}$ & $\mathbf{N}$ & $\mathbf{\%}$ & $\mathbf{N}$ & $\mathbf{\%}$ \\
$\mathbf{A}^{1}$ & 58 & 12.8 & 39 & 12.1 & 17 & 17.9 \\
$\mathbf{B}^{2}$ & 189 & 41.8 & 121 & 37.5 & 52 & 54.7 \\
$\mathbf{C}^{3}$ & 75 & 16.6 & 80 & 24.8 & 11 & 11.6 \\
$\mathbf{D}^{4}$ & 130 & 28.8 & 83 & 25.7 & 15 & 15.8 \\
Total & 452 & 100.0 & 323 & 100.0 & 95 & 100.0 \\
\hline
\end{tabular}

1. Direct quotation. 2. Specific, but interpreted, mention of a single work by Chatman. 3. Specific, but interpreted, mention of various works by Chatman. 4 . Non-specific mention

\section{Table 6 Citation style}

If we consider the incidents classified in categories $\mathrm{A}$ and $\mathrm{B}$ as essential, given that they relate to a specific work by Chatman, and regard those of categories C and D as superficial or perfunctory, as they form part of sentences in which various works are cited, the corresponding percentages for IPT and LRT are quite similar. In the case of IPT, essential cites would account for $54.6 \%$ of all incidents, with $45.4 \%$ counted as superficial or perfunctory. In the case of the LRT, the figure for essential cites would be $49.5 \%$ of all incidents, compared to a "superficial" total of $50.5 \%$. The "essential" and "superficial" figures for NBT would be $72.6 \%$ and $27.4 \%$ respectively.

The evolution of the citation style did not reveal a clear pattern in any of the three theories.

\subsubsection{Citation location}

A total of 146 documents with textual cites to the IPT, and an IMRD structure, contained 306 incidents; 103 documents citing the LRT contained 222 incidents, and 27 documents citing the NBT contained 43 incidents (table 4). 
The heading under which theoretical incidents appeared most frequently was Literature review, in the case of cites relating to IPT and LRT. In the case of cites referring to NBT, these appeared most frequently under Theoretical framework (table 7). Incidents relating to both IPT and LRT generally appeared more frequently under headings that described the general context of the research concerned ("Introduction" and "Literature review"); specifically $48.1 \%$ of incidents in the case of IPT and $41 \%$ in the case of LRT. Secondly, these theoretical incidents appeared under headings that contextualise the results of research ("Results", "Discussion" and "Conclusion"); specifically $32.7 \%$ of incidents in the case of the IPT and $40.2 \%$ in the case of LRT. The headings under which these incidents appeared less frequently were those concerned with the design of research ("Theoretical framework" and "Methods"); specifically $19 \%$ of incidents in the case of IPT and $18.5 \%$ in the case of LRT. Theoretical incidents relating to NBT appeared to an equal extent under all three group headings.

\begin{tabular}{llrrrrrr}
\hline & & IPT & & LRT & & \multicolumn{1}{c}{ NBT } \\
& & Total & \multicolumn{1}{c}{ \% } & Total & \% & Total & \% \\
\hline \multirow{3}{*}{ Research context } & Abstract & 1 & 0.3 & 1 & 0.5 & 3 & 7.0 \\
\cline { 2 - 8 } Research design & Introduction & 44 & 14.4 & 22 & 9.9 & 7 & 16.3 \\
& Literature rev. & 103 & 33.7 & 69 & 31.1 & 6 & 14.0 \\
\cline { 2 - 8 } Results context & Theoretical fram. & 44 & 14.4 & 36 & 16.2 & 12 & 27.9 \\
& Methods & 14 & 4.6 & 5 & 2.3 & 1 & 2.3 \\
\cline { 2 - 8 } & Results & 40 & 13.1 & 39 & 17.6 & 6 & 14.0 \\
& Discusion & 49 & 16.0 & 37 & 16.7 & 8 & 18.6 \\
& Conclusion & 11 & 3.6 & 13 & 5.9 & 0 & 0.0 \\
\hline
\end{tabular}

Table 7 Citation location

Whenever we relate the citation location to the citation style (table 8) we note, in the case of cites referring to IPT and LRT, that the style most commonly associated with incidents in the first part of the text $(\mathrm{I}+\mathrm{L})$ was non-specific mention (category $\mathrm{D})$. The most frequently occurring theoretical incidents in the middle and final sections of the document concerned belonged to category B (specific, but interpreted, mention of a single work by Chatman).

\begin{tabular}{|c|c|c|c|c|c|c|c|c|c|c|c|c|c|c|c|c|c|c|}
\hline & \multicolumn{6}{|c|}{ IPT } & \multicolumn{6}{|c|}{ LRT } & \multicolumn{6}{|c|}{ NBT } \\
\hline & $\mathbf{A}$ & B & $\mathrm{C}$ & D & $\mathbf{N}$ & $\%$ & $\mathbf{A}$ & $\bar{B}$ & $\mathbf{C}$ & D & $\mathbf{N}$ & $\%$ & $\mathbf{A}$ & $\mathbf{B}$ & $\mathbf{C}$ & D & $\mathbf{N}$ & $\%$ \\
\hline Abstract & & & 1 & & 1 & 0.3 & & 1 & & & 1 & 0,5 & & 2 & 1 & & 3 & 7,0 \\
\hline $\mathrm{I}+\mathrm{L}$ & 19 & 47 & 27 & 54 & 147 & 48.0 & 9 & 26 & 27 & 29 & 91 & 41,0 & 1 & 7 & 1 & 4 & 13 & 30,2 \\
\hline $\mathrm{T}+\mathrm{M}$ & 10 & 26 & 6 & 16 & 58 & 19.0 & 7 & 21 & 8 & 5 & 41 & 18,5 & 5 & 5 & 2 & 1 & 13 & 30,2 \\
\hline $\mathrm{R}+\mathrm{D}+\mathrm{C}$ & 10 & 59 & 15 & 16 & 100 & 32.7 & 9 & 44 & 18 & 18 & 89 & 40,1 & 2 & 10 & & 2 & 14 & 32,6 \\
\hline $\begin{array}{l}\text { Total } \\
\text { incidents }\end{array}$ & 39 & 132 & 49 & 86 & 306 & 100 & 25 & 92 & 53 & 52 & 222 & 100,0 & 8 & 24 & 4 & 7 & 43 & 100,0 \\
\hline
\end{tabular}

Of the 54 IPT-related theoretical incidents that appear in I+L, whose citation style was " $\mathrm{D}$ " (non-specific mention), only four (7.4\%) contained any of the four core concepts of this theory. Of the 26 that appeared in $\mathrm{T}+\mathrm{M}$, whose citation style was "B" (specific, but interpreted, mention of a single work by Chatman), a total of two (7.7\%) contained core concepts. Of the 59 that appeared in $\mathrm{R}+\mathrm{D}+\mathrm{C}$, likewise corresponding to style "B", 16 contained core concepts (27.1\%). Of the 29 LRT-related theoretical incidents that appear in $\mathrm{I}+\mathrm{L}$, whose citation style was " $\mathrm{D}$ " (non-specific mention), eight $(27.6 \%)$ contained one or another of the four core concepts of LRT.

Of the 21 LRT-related theoretical incidents that appeared in T+M, whose citation style was "B" (specific, but interpreted, mention of a single work by Chatman), a total of 12 (i.e. 57.4\%) contained one or another of the four core concepts. Of the 44 LRT-related theoretical incidents that appeared in $\mathrm{R}+\mathrm{D}+\mathrm{C}$, whose citation style was "B" (specific, but interpreted, mention of a single work by Chatman), a total of 24 (54.4\%) contained one or another of the four core concepts.

Figs. 7 and 8 show the evolution of the percentages of incidents appearing under each one of these three group headings for both IPT and LRT.

In the case of IPT (fig. 7), we can see that during most of the period studied more than $40 \%$ of incidents appeared in the introduction and literature review $(\mathrm{I}+\mathrm{L})$, with numbers decreasing up to the period from 2015 to 2017. Incidents appearing under the headings of "Theoretical framework" and "Methodology" 
$(\mathrm{T}+\mathrm{M})$ accounted for $30 \%$ of the total in the initial period from 1997 to 1999 , albeit with fluctuation throughout the period, before accounting for fewer than $20 \%$ of all incidents by the end of it. Finally, incidents that appeared in the results, discussion and conclusions $(\mathrm{R}+\mathrm{D}+\mathrm{C})$ initially accounted for $10 \%$ of the total in the period from 1997 to 1999 , albeit with fluctuations, before attaining a figure of more than $40 \%$ by the end of this period.

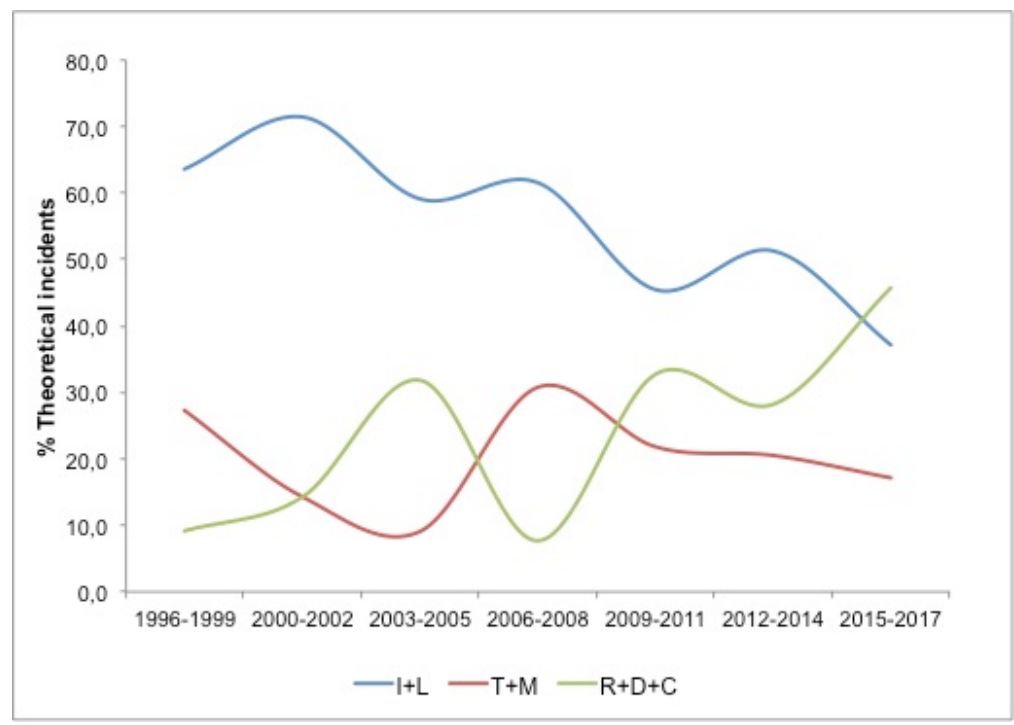

Fig 10 Information poverty theory: citation location in citing documents

LRT results from 2006 onwards are shown (fig. 11), as there were not enough incidents in the period before this (namely one in 1999, three between 2000 and 2002, and seven between 2003 and 2005). During the rest of the period, incidents that appear under $\mathrm{I}+\mathrm{L}$ and $\mathrm{R}+\mathrm{D}+\mathrm{C}$ constantly fluctuated between $30 \%$ and $50 \%$, with those under $\mathrm{T}+\mathrm{M}$ accounting for approximately $20 \%$. In the case of NBT finally, similar to what occurred in the initial years of LRT, there were insufficient incidents to allow the identification of an evolving pattern of incident location.

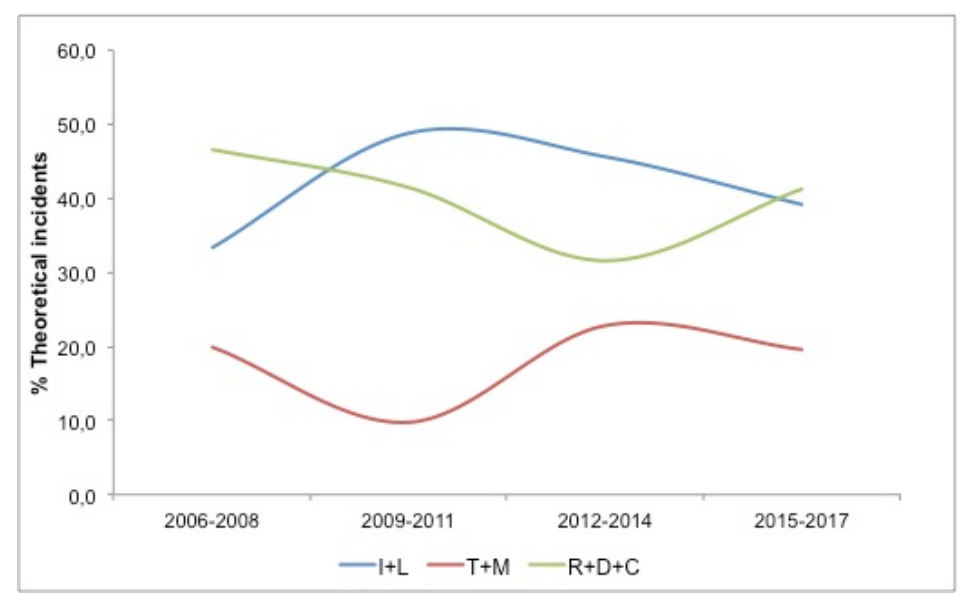

Fig 11 Life in the round theory: citation location in citing documents

\section{DISCUSSION}

There are no doubts regarding the recognition and professional career of Elfreda Chatman, given that references to her are obligatory in any research involving IB in everyday life, particularly when talking about disadvantaged populations. The articles included in IPT and LRT are therefore two of the most widely cited core theoretical documents in IB research (González et al, 2015). Working on the basis of citation of three of these articles, this research explores the impact of the three theories proposed by Chatman. An analysis of citation in context has allowed us to draw a distinction between the author and 
her work, while verifying that not all cites are the same. These differences reflect the unequal relevance of these theories to subsequent research.

The results demonstrate this twin perspective of citation analysis. From the point of view of absolute number of citations, IPT is the theory with greater impact, followed by LRT and NBT.

With regard to the first two theories, since Chatman published her works of 1996 and 1999, these have been steadily and increasingly cited until the present day. This may be due to the growth of literature in IB (Wilson, 2008) and, within that, the ever-increasing importance of research into everyday life information seeking (ELIS). The continuous and growing frequency of citation throughout this period has led some authors to categorise the works concerned as classics (Chang, 2016). Chatman (1996) and Chatman (1999) are, despite not being among the works most cited in LIS (Yang, 2009), two of the most cited works in literature about IB (González-Teruel, 2017).

The same is not true of NBT, as it is cited very infrequently in absolute terms with no progression during the period concerned. Although collaborators of Chatman (e.g. Burnett et al., 2008) are continuing with this line of work, the author's death appears to have resulted in the last of her middle-range theories being forgotten. It is in fact the only one of her three theories that does not appear in the list of more than 70 compiled by Fisher, Erderlez and McKechnie (2005). NBT nevertheless includes concepts and propositions already dealt with in previous works (Chatman 2000) and it is, as Savolainen (2008) states, a further elaboration and extension of LRT.

The differing impact of IPT and LRT on one hand and of NBT on the other is also reflected in the type of works cited. Most citing works corresponding to the first two theories are empirical, with particular reference to the period from 2006 to 2008. This denotes a greater assimilation of these theories, since only empirical strategies allow us to add new observations that validate or refute the initial concepts and propositions concerned. This result also agrees with the findings of Tuomaala, Järvelin and Vakkari (2014) regarding the increasing use of empirical research strategies in investigation into LIS from the year 2005 onwards. In the case of NBT however, bibliographical works are disproportionately important among citing works overall, with an increase in empirical strategies only after the period between 2009 and 2011.

The impact of Chatman's three works in areas other than LIS is not high. We can generally say that the longer the observed citation period is, the more cites correspond to other areas. IPT therefore accounts for a higher percentage than non-LIS citing works, at $17.4 \%$; followed by LRT at $10.5 \%$. The result in both cases was greater than that obtained by Chang (2013) with respect to the work of Taylor (1968), which accounted for $8.1 \%$. It is nevertheless considerably less than that of Chang (2016) with regard to Zipf's principle of least effort (1949). The latter was cited in publications belonging to 40 different disciplines. The one accounting for most of these cites (computer science) did so with just $20.8 \%$ of the total number. These corroborate the findings of Fisher and Julien (2009) regarding the limited interest created by IB in other disciplines, in contrast to the potential interest that it should provoke. The increasing number of cites from other disciplines could nevertheless be responding to the conversion of LIS into a discipline that imports cites rather than one that exports them (Cronin \& Meho, 2008).

Apart from the absolute citation figures, when we take a deeper look at these citations in context, the results may be qualified equally in terms of the frequency of their occurrence, their contents, their style or their position within the citing document.

When it comes to the frequency of incidents by document, the first result that draws our attention is the fact that more than half of the citing works include only one reference to the work of Chatman (IPT $64.4 \%$, LRT- 53.8\%, NBT- 65.3). This result is consistent with similar works (Taskin, 2017). However, this fact - coupled with a minimal increase in average incidents per article throughout the period - does not reveal any essential contribution to the works concerned. They are on the contrary an indication of low contribution, given that any evaluation of such a contribution on the part of bibliographical reference needs to take into account the number of times that the item concerned is cited in the same document (Ding et al. 2013). Zhu et al (2015), on the other hand, find that the number of times a reference is mentioned in the body of a citing paper is the main indicator used to determine an author's academic influence. The works covered by this research which most frequently cited Chatman (1996) and Chatman (1999) were in fact Veinot (2009) and Dankasa (2017). IPT and LRT provided the theoretical basis in both cases, thereby indicating a high degree of assimilation of Chatman's theories. The percentages corresponding to single theoretical incidents nevertheless vary among the three theories. LRT corresponds in this respect to a greater number of recurring incidents per document, which would indicate a greater relevance on the part of Chatman (1999) for the citing works. It is in this way that this initial caveat leads us to think that the most widely cited document is not necessarily the one with most 
influence on subsequent research. We can therefore say, in terms of the influence that a theory has on subsequent research, that the theory most cited is not the most influential or the most assimilated.

Secondly, analysis of the terms and expressions that appeared in theoretical incidents revealed cited content in at least $4 \%$ of theoretical incidents. This range nevertheless included, for the three theories and the four core concepts that underpin it, a very low (but also differentiated) percentage of incidents and documents containing these items. The theory with the largest number of absolute citations, IPT, obtained a lower number of theoretical incidents containing other concepts (35\%) than the next in the list in terms of number of absolute citation, namely LRT $(45.8 \%)$. At the same time, the theory with the lowest number of cites, NBT, accounted for only $48 \%$ of incidents in which these concepts were present. The core concepts of NBT nevertheless include the expression "information behaviour", which could also be used as such as a generic expression within the line of research concerned. Likewise, and in the case of LRT, "small world" is an expression which is both a core concept of this theory and a term used to refer in general to the theories of Chatman or the communities on which her research was centred. It is therefore possible that these results are distorted. Nevertheless, and in the case of LRT, if we relate this to the number of single incidents per document (which is lower than that of the other two theories), this could indicate a greater degree of assimilation on the part of this theory. More research would be needed in this respect.

The analysis of the co-occurrences of terms in context, along with the calculation of the frequency of terms and concepts, has allowed to obtain the knowledge structure of the corpus of texts (Small, 1980) that cite the three Chatman theories. This structure identifies the ideas symbolized by the cited work and the degree of consensus among the papers and authors that cite it (Small, 1978). In such a way, it hereby represents in graphic form the repercussion that the three Chatman theories have had in the subsequent research. In this particular case, the low frequency of co-occurrences observed between terms versus possible co-occurrences between concepts (except for the concepts of "insider" and "outsider"), suggests a low consensus among the citing work. This makes us think that the quotes to the three Chatman theories do not impact in common aspects and that the concepts involved in these three theories are hardly discussed. This would denote that the quotes to the three Chatman theories are made as a general referent without deepening in the theoretical statements. This result reinforces the previous one obtained, by finding the frequency of occurrence of terms.

Thirdly, and with respect to citation style, our attention is drawn to the lower incidence of direct quotations concerning IPT and LRT. It is important in this respect to highlight the work of Rosenbaum (2010), in which he studied the assimilation into LIS of the theories of Giddens. This researcher obtained a figure of 54\% for "ceremonial" cites, in the sense of those that "[cite] one or another monograph or article without providing a page number or quoting any text from the cited work" (Rosenbaum, 2010, p.125). According to this, if we also add, to the low number of direct quotations, the low number of incidents that include one or another of the core concepts of the two theories concerned, we could speak of a large number of such "ceremonial" citations which refer to the author's authority rather than to the content of his or her work. However, if we also consider as essential those cites that refer to a specific work of Chatman (categories A and B), in contrast to those considered superficial and non-specific, which include works by Chatman and various other authors (categories $\mathrm{C}$ and $\mathrm{B}$ ), the percentages for IPT and LRT respectively would be fairly balanced. This is not the case for NBT, which accounts for more than $70 \%$ of essential citations. It is, once more, not the most widely cited theory in absolute terms of the most relevant incidents obtained, as defined in this case by the style of citation.

With respect to the citation location in a document, the results agree with those of Boyack, Eck, Colavizza, and Waltman (2018) which recognise the existence of a consensus in the literature concerned regarding the citation location. These researchers state that cites tend to be more concentrated at the beginning (introduction and literature review) and end of a text (discussion and conclusion), rather than in the middle part of the work. Boyack et al. (2018) likewise assert that cites which appear outside the introductory sections of a text tend to be the most useful. This is confirmed in the case of IPT and LRT, where the incidents most frequently included in the initial sections of the document are those classed as non-specific (category D).

The relevance of theoretical incidents could be deduced from the relationship between citation location, citation style and the presence or absence of theoretical core concepts. The citations that we consider to be most relevant would therefore appear in the "Results", "Discussion" or "Conclusion" sections, as the parts in which results are compared and discussed. The next on the list in terms of relevance would be those that appear in the introduction and literature review, i.e. the sections that put the research into context. The least relevant items, finally, would appear in the "Theoretical framework" and "Methods" 
sections, which describe the basis of the research. In the light of the above, the degree of theory assimilation is therefore low.

In the case of IPT, if we compare this to the pattern established by Lu et al. (2017) with respect to the existence of three successive phases in the citation cycle of a given work (discussion, reputation and adoption), the results indicate a low take-up of the theory. There would be, in the IPT-related citation, an initial phase clearly identifiable in terms of the "reputation" phase of Lu et al. (2017), in which more than $70 \%$ of incidents appear in the introduction and literature review. This corresponds to the period 20002002. There was, secondly, an adoption phase in the period from 2006 to 2008, in which a large percentage of incidents appeared under "Theoretical framework" and "Methodology", although this percentage dropped during the rest of the period, thereby giving relative importance to any possible adoption. There was finally a third phase in the period from 2015 to 2017, in which most incidents appeared in the results, discussion or conclusion sections, which would correspond to the "discussion" phase cited by Lu et al. (2017). If we therefore take this reference as a model, it might be considered, in the case of IPT, that its influence after the publication of the work of Chatman (1996) is related to her reputation for being one of the first researchers to attempt to construct a theoretical framework for the study of IB. However, discussion of the subject with respect to comparison and contextualisation of the results of research into LIS is recent, and it has not been widely adopted as a basis for designing research in this area. In the case of LRT and NBT, the low number of theoretical incidents in documents with an IMRD structure prevented any carrying-out of this type of comparison.

Despite the limits on analysis created by the existence of citing works that contain no citation in text, and of documents without an IMRD structure, the results presented here allow us to determine the influence of Chatman's theories and, in part, their assimilation into subsequent research. Neither the recognition of an author by the academic community nor the total number of times that his or her work is cited can be considered an absolute indicator of that work's influence on subsequent research. The assimilation of Chatman's theories is not as extensive as might be indicated by the total number of times that she is cited, but it is likewise not as low as alleged by Burnett et al. (2008). We have in this case detected the relevance of citations relating to the three works used for reference purposes. The cites (and thus, by extension, the citing works) found to the most relevant could be the starting point for further and deeper research into such theoretical incidents in the context of the documents and research to which they refer. This facilitates a critical reading of the antecedents of a programme of research and returns us, if necessary, to the original source-text, which is the true reflection of the contributions made by the author concerned. Only in this way is it possible to build on the basis of existing knowledge, obtain comparable results and generate new scientific knowledge. Only in this way is it possible to escape from the impasse that characterises current research into IB, with hundreds of theoretical proposals arising from other disciplines and theoretical models based on partial observations of reality, without any apparent connection between them.

\section{REFERENCES}

Anderson, M. H. (2006). How Can We Know What We Think Until We See What We Said?: A Citation and Citation Context Analysis of Karl Weick's The Social Psychology of Organizing. Organization Studies, 27(11), 1675-1692. http://doi.org/10.1177/0170840606068346

Anderson, M. H., \& Sun, P. Y. T. (2010). What have scholars retrieved from Walsh and Ungson (1991)? A citation context study. Management Learning, 41(2), 131-145. http://doi.org/10.1177/1350507609341091

APA. American Psychological Association. (2010). Publication manual of the American Psychological Association (6 ed.). Washington: American Psychological Association

Bardin, L. (1986). El análisis de contenido. Madrid: Akal.

Bonzi, S. (1982). Characteristics of a Literature as Predictors of Relatedness Between Cited and Citing Works. Journal of the American Society for Information Science and Technology, 33(4), 208-216. http://doi.org/10.1002/asi.4630330404

Boyack, K. W., van Eck, N. J., Colavizza, G., \& Waltman, L. (2018). Characterizing in-text citations in scientific articles: A large-scale analysis. Journal of Informetrics, 12(1), 59-73. http://doi.org/10.1016/j.joi.2017.11.005

Brooks, F. P. (1975) The Mythical Man-Month. Essays on Software Engineering. Reading, MA: AddisonWesley. 
Burnett, G., \& Jaeger, P. T. (2008). Small worlds, lifeworlds, and information: The ramifications of the information behaviours of social groups in public policy and the public sphere. Information Research, 13(2). Retrieved from InformationR.net/ir/13-2/paper346.html

Burnett, G., \& Nocasian, M. (2008). A Romania of the imagination: Formula As, virtual community, and normative behavior. First Monday, 13(11). http://doi.org/10.5210/fm.v13i11.2257

Burnett, G., Besant, M., \& Chatman, E. A. (2001). Small worlds: Normative behavior in virtual communities and feminist bookselling. Journal of the American Society for Information Science and Technology, 52(7), 536-547. http://doi.org/10.1002/asi.1102.abs

Burnett, G., Fisher, K. E., Fulton, C., \& Hersberger, J. A. (2007). Channelling chatman: Questioning the applicability of a research legacy to today's small world realities. Proceedings of the American Society for Information Science and Technology, 43(1), 1-7. http://doi.org/10.1002/meet.1450430197

Burnett, G., Jaeger, P. T., \& Thompson, K. M. (2008). Normative behavior and information: The social aspects of information access. Library and Information Science Research, 30(1), 56-66. http://doi.org/10.1016/j.lisr.2007.07.003

Case, D. O., \& Given, L. M. (2016). Looking for information: a survey of research on information seeking, needs, and behavior (4 ed.). Bingley: Emerald.

Chang, Y.-W. (2013). The influence of Taylor's paper, Question-Negotiation and Information-Seeking in Libraries. Information Processing \& Management, 49(5), 983-994. http://doi.org/10.1016/j.ipm.2013.03.003

Chang, Y.-W. (2016). Influence of human behavior and the principle of least effort on library and information science research. Information Processing \& Management, 52(4), 658-669. http://doi.org/10.1016/j.ipm.2015.12.011

Chatman, E. A. (1996). The impoverished life-world of outsiders. Journal of the American Society for Information Science, 47(3), 193-206. http://doi.org/\{10.1002/(SICI)1097-4571(199603)47:3<193::AIDASI3>3.0.CO;2-T

Chatman, E. A. (1999). A theory of life in the round. Journal of the American Society for Information Science, 50(3), 207-217. http://doi.org/\{10.1002/(SICI)1097-4571(1999)50:3<207::AIDASI3>3.0.CO;2-8\}

Chatman, E. A. (2000). Framing social life in theory and research. The New Review of Information Behaviour Research, 1, 3-17. http://doi.org/\{10.1016/S0306-4573(00)00021-2\}

Cronin, B., \& Meho, L. I. (2008). The shifting balance of intellectual trade in information studies. Journal of the American Society for Information Science and Technology, 59(4), 551-564. http://doi.org/doi.org/10.1002/asi.20764

Dankasa, J. (2017). Seeking information in circles: The application of Chatman's life in the round theory to the information small world of Catholic clergy in northern Nigeria. Journal of Information Science, 43(2), 246-259. http://doi.org/10.1177/0165551516632659

Ding, Y., Liu, X., Guo, C., \& Cronin, B. (2013). The distribution of references across texts: Some implications for citation analysis. Journal of Informetrics, 7(3), 583-592. http://doi.org/10.1016/j.joi.2013.03.003

Ellis, D. (1989). A behavioural approach to information retrieval system design. Journal of Documentation, 45(3), 171-212. http://doi.org/10.1108/eb026843

Fidel, R. (2012). Human Information Interaction. MIT Press.

Fisher, K. E., \& Julien, H. (2011). Information behavior. Annual Review of Information Science and Technology, 43, 1-73. http://doi.org/10.1002/aris.2009.1440430114

Fisher, K. E., \& Julien, H. (2017). Information Behavior. Annual Review of Information ..., 43, 1-22.

Fulton, C. (2010). An Ordinary Life in the Round: Elfreda Annmary Chatman. Libraries \& the Cultural Record, 45(2), 238-259. http://doi.org/10.1353/lac.0.0122

González-Teruel, A. (2017). Referentes teóricos y dimensiones aplicadas en el estudio del usuario de la información. In M. N. González de Gómez \& R. Rabello (Eds.), Informação: agentes e intermediação (pp. 135-194). Brasilia: Instituto Brasileiro de Informaçao em Ciencia e Tecnologia.

González-Teruel, A., González-Alcaide, G., Barrios, M., \& Abad-García, M. F. (2015). Mapping recent information behavior research: an analysis of co-authorship and co-citation networks. Scientometrics, 103(2), 687-705. http://doi.org/10.1007/s11192-015-1548-z

Hirsch, J. E. (2005). An index to quantify an individual's scientific research output. Proceedings of the 
National Academy of Sciences of the United States of America, 102(46), 16569-16572.

Lu, C., Ding, Y., \& Zhang, C. (2017). Understanding the impact change of a highly cited article: a content-based citation analysis. Scientometrics, 112(2), 927-945. http://doi.org/10.1007/s11192-0172398-7

McCain, K. W. (2011). Eponymy and Obliteration by Incorporation: The case of the "Nash Equilibrium." Journal of the American Society for Information Science and Technology, 62(7), 1412-1424. http://doi.org/10.1002/asi.21536

McCain, K. W., \& Salvucci, L. J. (2006). How influential is Brooks' Law? A longitudinal citation context analysis of Frederick Brooks' The Mythical Man-Month. Journal of Information Science, 32(3), 277-295. http://doi.org/10.1177/0165551506064397

McKechnie, L., Pettigrew, K. E., \& Joyce, S. L. (2001). The origins and contextual use of theory in human information behaviour research. The New Review of Information Behaviour Research, 1, 47-63.

Pettigrew, K. E., Fidel, R., \& Bruce, H. (2001). Conceptual frameworks in information behavior. Annual Review of Information Science and Technology, 35, 43-78

Rosenbaum, H. (2010). Anthony Giddens' Influence on Library and Information Science. In: Leckie, G. J., Given, L. M., \& Buschman, J. (2010). Critical theory for Library and Information Science (pp. 119130). Santa Barbara, CA: ABC CLIO.

Savolainen, R. (2008). Everyday Life Information Seeking. In Encyclopedia of Library and Information Science (pp. 155-163). Taylor \& Francis Group.

Savolainen, R. (2016a). Contributions to conceptual growth: The elaboration of Ellis's model for information-seeking behavior. Journal of the Association for Information Science and Technology, 68(3), 594-608. http://doi.org/10.1002/asi.23680

Savolainen, R. (2016b). Conceptual growth in integrated models for information behaviour. Journal of Documentation, 72(4), 648-673. http://doi.org/10.1108/JDOC-09-2015-0114

Sieweke, J. (2014). Pierre Bourdieu in management and organization studies - A citation context analysis and discussion of contributions. Scandinavian Journal of Management, 30(4), 532-543. http://doi.org/10.1016/j.scaman.2014.04.004

Small, H. (1978). Cited documents as concept symbols. Social Studies of Science, 8(3), 327-340. http://doi.org/10.1177/030631277800800305

Small, H. (1980). Co-citation context analysis and the structure of paradigms. Journal of Documentation, 36(3), 183-196. http://doi.org/10.1108/eb026695

Spink, A., \& Cole, C. (2005). Human information behavior: Integrating diverse approaches and information use. Journal of the American Society for Information Science and Technology, 57(1), 25-35. http://doi.org/10.1002/asi.20249

Taskin, Z., \& Al, U. (2017). A content-based citation analysis study based on text categorization. Scientometrics, 1-23. http://doi.org/10.1007/s11192-017-2560-2

Taylor, R. S. (1968). Question-negotiation and information seeking in libraries. College \& Research Libraries, 28, 178-194.

Tsay, M.-Y. (2009). Citation analysis of Ted Nelson's works and his influence on hypertext concept. Scientometrics, 79(3), 451-472. http://doi.org/10.1007/s11192-008-1641-7

Tuomaala, O., Järvelin, K., \& Vakkari, P. (2014). Evolution of library and information science, 19652005: Content analysis of journal articles. Journal of the Association for Information Science and Technology, 65(7), 1446-1462. http://doi.org/10.1002/asi.23034

Vakkari, P. (1998). Growth of theories on information seeking: An analysis of growth of a theoretical research program on the relation between task complexity and information seeking. Information Processing \& Management, 34(2-3), 361-382. http://doi.org/10.1016/S0306-4573(97)00074-5

Veinot, T. (2010). "A lot of people didn't have a chance to support us because we never told them" Stigma management, information poverty and HIV/AIDS information/help networks. Proceedings of the American Society for Information Science and Technology, 46(1), 1-20. http://doi.org/10.1002/meet.2009.1450460273

Walsh, J. P., \& Ungson, G. R. (1991). Organizational memory. Academy of Management Review, 16(1), $57-91$.

Wilson, T. (2008). The information user: past, present and future. Journal of Information Science, 34(4), 457-464. http://doi.org/10.1177/0165551508091309 
Yang, H. (2009). The top 40 citation classics in the Journal of the American Society for Information Science and Technology. Scientometrics, 78(3), 421-426. http://doi.org/10.1007/s11192-007-2011-6

Zhang, G., Ding, Y., \& Milojević, S. (2013). Citation content analysis (CCA): A framework for syntactic and semantic analysis of citation content. Journal of the American Society for Information Science and Technology, 64(7), 1490-1503. http://doi.org/10.1002/asi.22850

Zhu, X., Turney, P., Lemire, D., \& Vellino, A. (2014). Measuring academic influence: Not all citations are equal. Journal of the Association for Information Science and Technology, 66(2), 408-427. http://doi.org/10.1002/asi.23179

Zipf, G. K. (1949). Human behavior and the principle of least effort. Boston: Addison-Wesley Press. 